This article was downloaded by: [Indian Institute of Technology Kanpur]

On: 02 August 2012, At: 20:51

Publisher: Taylor \& Francis

Informa Ltd Registered in England and Wales Registered Number: 1072954 Registered office: Mortimer House, 37-41 Mortimer Street, London W1T 3J H, UK

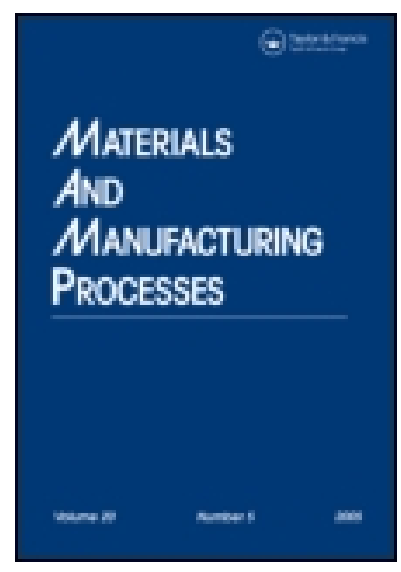

\title{
Materials and Manufacturing Processes
}

Publication details, including instructions for authors and subscription information: http:// www. tandfonline.com/loi/ Immp20

\section{Nano-Cutting Fluid for Enhancement of Metal Cutting Performance}

S. Khandekar ${ }^{a}$, M. Ravi Sankar ${ }^{a}$, V. Agnihotri $^{\text {a }}$ \& J. Ramkumar ${ }^{a}$

${ }^{a}$ Department of Mechanical Engineering, Indian Institute of Technology, Kanpur, India

Accepted author version posted online: 03 Oct 2011. Version of record first published: 01 Aug 2012

To cite this article: S. Khandekar, M. Ravi Sankar, V. Agnihotri \& J. Ramkumar (2012): Nano-Cutting Fluid for Enhancement of Metal Cutting Performance, Materials and Manufacturing Processes, 27:9, 963-967

To link to this article: http:// dx.doi.org/ 10.1080/ 10426914.2011.610078

\section{PLEASE SCROLL DOWN FOR ARTICLE}

Full terms and conditions of use: http://www.tandfonline.com/page/terms-and-conditions

This article may be used for research, teaching, and private study purposes. Any substantial or systematic reproduction, redistribution, reselling, loan, sub-licensing, systematic supply, or distribution in any form to anyone is expressly forbidden.

The publisher does not give any warranty express or implied or make any representation that the contents will be complete or accurate or up to date. The accuracy of any instructions, formulae, and drug doses should be independently verified with primary sources. The publisher shall not be liable for any loss, actions, claims, proceedings, demand, or costs or damages whatsoever or howsoever caused arising directly or indirectly in connection with or arising out of the use of this material. 


\title{
Nano-Cutting Fluid for Enhancement of Metal Cutting Performance
}

\author{
S. Khandekar, M. Ravi Sankar, V. Agnihotri, and J. Ramkumar \\ Department of Mechanical Engineering, Indian Institute of Technology, Kanpur, India
}

\begin{abstract}
Nano-cutting fluids are the mixtures of conventional cutting fluid and nanoparticles. Addition of the nanoparticles can alter wettability, lubricating properties, and convective heat transfer coefficient (cooling properties) of nano-cutting fluids. In the present work, nano-cutting fluid is made by adding $1 \% \mathrm{Al}_{2} \mathrm{O}_{3}$ nanoparticles to conventional cutting fluid. The wettability characteristic of this nano-cutting fluid on a carbide tool tip is measured using the macroscopic contact angle method. Comparative study of tool wear, cutting force, workpiece surface roughness, and chip thickness among dry machining, machining with conventional cutting fluid as well as nano-cutting fluid has been undertaken. This study clearly reveals that the cutting force, workpiece surface roughness, tool wear, and chip thickness are reduced by the using nano-cutting fluid compared to dry machining and machining with conventional cutting fluid.
\end{abstract}

Keywords Chips; Force; Morphology; Roughness; Wear; Wettability.

\section{INTRODUCTION}

The most desirable properties of cutting fluids are cooling (superior convective and conductive heat transfer coefficient), lubrication, and evacuation of chips from machining zone. Cooling is one of the most important challenges in the machining process faced by numerous industries such as automobiles, electronics, and manufacturing [1-5]. New technological developments are increasing thermal loads that require faster cooling. The conventional methods of enhancing the cooling rate are already stretched to their limits [6-10]. Hence, there is need for new and innovative cutting fluids to achieve this high performance cooling [11, 12].

Nano-cutting fluid is one of the novel concepts, wherein nanoparticles are suspended in conventional cutting fluid, which are being developed to meet more demanding cooling and lubricating challenges in machining. Several researchers showed that the convective heat transfer coefficient increases substantially for nanofluids [13-18].

The present work aims at demonstrating the possibility of enhancing the desired properties of a cutting fluid by adding suitable nanoparticles and forming stable nano-cutting fluids. Recent studies indicated that suspended nanoparticles can alter the thermophysical and transport properties of the conventional cutting fluids. A small amount of copper nanoparticles (less than $1 \%$ vol. fraction) or carbon nanotubes dispersed in ethylene glycol can increase the poor thermal conductivity of ethylene glycol by $40 \%$ to $150 \%$. The thermal conductivity of nanofluids increases nonlinearly with temperature [19]. Kim and Bang show that addition of nanoparticles enhances the wettability of the base fluids

Received March 30, 2011; Accepted July 13, 2011

Address correspondence to J. Ramkumar, Department of Mechanical Engineering, Indian Institute of Technology, Kanpur, India; E-mail: jrkumar@iitk.a.c.in, janakarajanramukumar@gmail.com
[20]. Nanoparticles near the liquid-solid surface can enhance the wettability characteristics of the base fluid [21-23].

Thus, the introduction of nano-cutting fluids has opened up the new possibility of enhancing the thermophysical properties of the base fluids in a desired manner. In tune with emerging trends, the present study reports the successful application of $\mathrm{Al}_{2} \mathrm{O}_{3}$ based nano-cutting fluids for machining operation.

In the present study, a special type of nano-cutting fluid is developed by mixing self-synthesized $\mathrm{Al}_{2} \mathrm{O}_{3}$ nano particles into the conventional cutting fluid. The wettability of water, conventional cutting fluid, and nanocutting fluids is measured using macroscopic contact angle method. The comparative wettability study is to demonstrate the better wettability characteristics of nano-cutting fluids compared to other two fluids. Later, cutting performance is compared among dry machining, machining with conventional cutting fluid, and nanocutting fluid in terms of tool wear (crater wear and flank wear), cutting force, average surface roughness, and chip thickness.

\section{EXPERIMENTATION}

\section{Materials Selection and Equipment}

Various equipments and materials (with their specifications) that are used in the present experimental study are given in the Table 1.

\section{Selection of Input Parameters}

The input parameters for the present study are selected and given in the Table 2.

\section{Formulation of Nano-Cutting Fluid}

The nano-cutting fluid is prepared by adding $1 \%$ by volume of self-synthesised $\mathrm{Al}_{2} \mathrm{O}_{3}$ nanoparticles to the emulsion type cutting fluid (Servo-Cut-'S'). Later, this 
TABLE 1.- Materials and equipment

\begin{tabular}{ll}
\hline Workpiece & AISI 4340 ( $\Phi 100 \mathrm{~mm}$ X 500 mm) \\
Cutting tool & Uncoated cemented carbide insert (TPUN 16-03-08) \\
Machine tool & LB/17 Lathe (HMT, India) \\
Cutting fluid & $\begin{array}{c}\text { Servo Cut "S" }+ \text { Additives }+\mathrm{Al}_{2} \mathrm{O}_{3} \text { nanoparticles } \\
\quad+\text { Water }\end{array}$ \\
$\begin{array}{c}\text { Surf analyzer } \\
\text { Tool wear } \\
\text { analyzer }\end{array}$ & $\begin{array}{l}\text { Scanning electron microscope, Optical microscope } \\
\end{array}$ \\
\hline
\end{tabular}

mixture is subjected to ultrasonication for about two hours. It results in a stable nano-cutting fluid and no precipitation/settlement of particles is observed during entire machining process.

\section{Experimental Procedure}

Preliminary experimentation is carried out for dry machining and machining with conventional and nanocutting fluids to find the optimum range of various input parameters, i.e., feed rate, cutting velocity, and depth of cut (Table 2). Later, complete experiments are carried out in dry machining and machining with conventional and nano-cutting fluids conditions, respectively, to find the relative advantage of nano-cutting fluid over the other two.

Cutting force $\left(\mathrm{F}_{\mathrm{C}}\right)$ during the machining trials is recorded with the aid of a piezoelectric tool-post dynamometer. Surface roughness values of the machined workpiece at five locations are recorded using a stylus type surface profilometer (Federal Surf Analyzer 5000). The average of five surface roughness values is calculated and represented as the average surface roughness $\left(R_{a}\right)$ value of the machined surface. Flank wear measurement and morphology is studied using optical microscope. Chip thickness and chip morphology is also analyzed for comparison of three machining processes.

\section{RESULTS AND DISCUSSION}

\section{Wettability Study of Nano-Cutting Fluid}

The wettability characteristics of fluid on a particular solid substrate can be estimated by the measurement of macroscopic contact angle between the fluid droplet and the solid substrate surface. In most applications, air is always present as the third phase. Thus, the equilibrium thermodynamic contact angle is given by Young's equation (Fig. 1) [24]:

$\cos \theta=\frac{\sigma_{s v}-\sigma_{s l}}{\sigma_{l v}}$

TABle 2.- Process input parameters

\begin{tabular}{ll}
\hline Cutting time (t) & $50,100,150,200,250,300,350(\mathrm{sec})$ \\
Feed (f) & $0.1(\mathrm{~mm} / \mathrm{rev})$ \\
Cutting velocity (V) & $350(\mathrm{~m} / \mathrm{min})$ \\
Depth of cut (d) & $1.0(\mathrm{~mm})$ (radially) \\
Machining & (i) dry machining \\
environments & (ii) Machining with conventional cutting fluid \\
& (iii) Machining with nano-cutting fluid \\
\hline
\end{tabular}

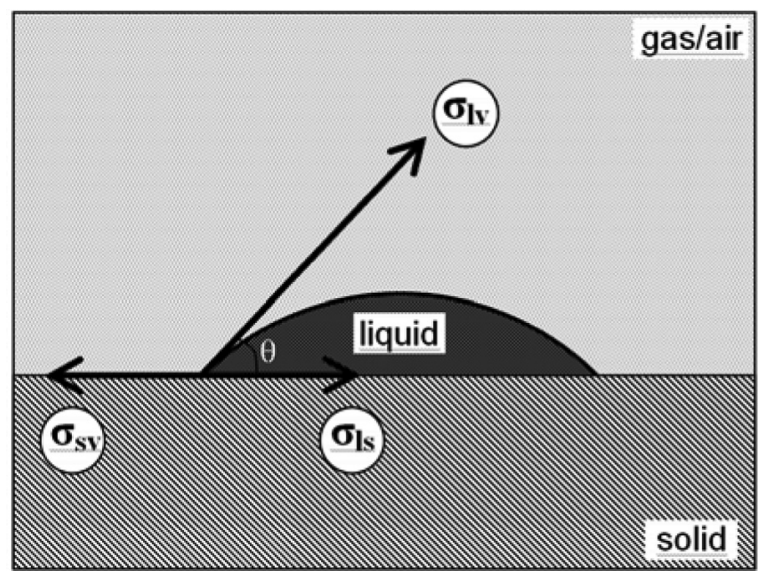

Figure 1.-Schematic showing a droplet of liquid on a solid surface.

Alternatively, the macroscopic contact angle can also be viewed as the manifestation of the interaction of adhesive/cohesive forces acting on the contact line, i.e.,

$\cos \theta=\frac{\text { Net adhesion force }}{\text { Surface tension force }}$

From a thermodynamic point of view, spreading of the liquid droplet ensures minimization of Helmholtz free energy, leading to the definition of equilibrium contact angle, i.e.,

$\frac{\partial F_{H}}{\partial A_{s l}}=\sigma_{s l}+\sigma_{l v}-\sigma_{s v}$.

The free energy of a system depends on the intermolecular force potentials of the constituent molecules/ atoms (van der Waals forces, Debye forces, Keesom forces, Hydrogen bonds, Covalent bonds, etc.). These interactive forces also give rise to the phenomenon of surface tension. It is known that the net surface tension of liquids strongly depends on the Van der Walls forces. The interaction length scale of these forces is of the order of $1 \mathrm{~nm}$ to $100 \mathrm{~nm}$, which is the size of the nanoparticles. So, it is expected that addition of nanoparticles affects the net free energy of a pure fluid-solid-air interface.

To check this hypothesis, macroscopic contact angles of pendant droplets of pure water, conventional cutting fluid, and nano-cutting fluid, respectively, are measured by a goniometer on a cutting tool insert (TPUN 16-03-08). It is clearly seen that the wettability of nanocutting fluid is substantially better than that of pure water and conventional cutting fluid (Fig. 2). All the measurements are performed at room temperature $\left(27^{\circ} \mathrm{C}\right)$, and the droplet volume of $10 \mu \mathrm{l}$ is used. Droplet sizes in all measurements are ensured by a micrometering syringe. The repeatability of the contact angle data is observed within $\pm 5 \%$.

The data clearly suggest that the nanoparticles affect the adhesive/cohesive force interactions at the contact line. Also, the wetting area per unit volume in the case of nano-cutting fluid droplet increases. So, it enhances 


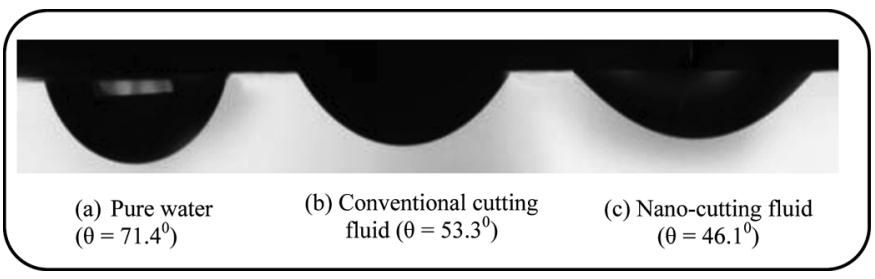

FIGURE 2.- Images of pendant droplets of (a) pure water, (b) conventional cutting fluid, and (c) nano-cutting fluid on carbide tool substrate.

the lubricating and heat removal properties compared to the conventional cutting fluid.

\section{Tool Wear}

In the present study, tool wear refers to the morphology of crater and flank wears. The temperature generated in the primary and secondary shear zone affects the wear of tool materials. The existence of high cutting temperature and stress at the cutting edge, coupled with the brittleness of the tool material, accelerates the chipping, cracking, and fracture of the tool inserts. This is commonly seen in dry machining process due to the absence of cutting fluid. So, crater wear is high in dry machining (Fig. 3(a)). Due to continuous rubbing of the machined work surface on the thermally softened flank face and absence of cutting fluid leads to severe flank wear (Fig. 3(b)).

Conventional cutting fluids provide lubrication and partially reduce the generated heat in machining zone compared to dry condition. But due to dominant adhesive wear mode, crater wear is observed near the tool cutting edge. Adhesive wear mechanism depends on the adhesive affinity of tool and workpiece, the hot strength of the tool material at the adhesive junction, and the frequency of interruptions at the adhesive contact. Weak interface bonding between tool and workpiece surfaces increase the severity of adhesion wear. The adhered workpiece surface layer often remains attached to the tool edge. Thus the crater wear is observed at the seizure zone of machining (Fig. 3(c)). Continuous rubbing of workpiece with the flank face tries to chip-off tool flank surface layers. But, because of conventional cutting fluid lubrication ability, the tool retains its hardness and thus flank wear partially reduces compared to dry machining process (Fig. 3(d),(e)). In case of nano-cutting fluid, because of its better conduction, convection, and wettability compared to conventional cutting fluid, both tool wears (crater and flank wear) reduce enormously and are just confined minimally to cutting edge region only. Due to better cooling and lubrication properties of nanocutting fluid, the tool retains its original hardness for longer times (Fig. 3(f)). Thus the flank wear is minimum compared to the other two processes (Fig. 3(g)).

\section{Cutting Force}

As machining starts, in the initial stage the cutting forces are less as the tool is sharp and machining is
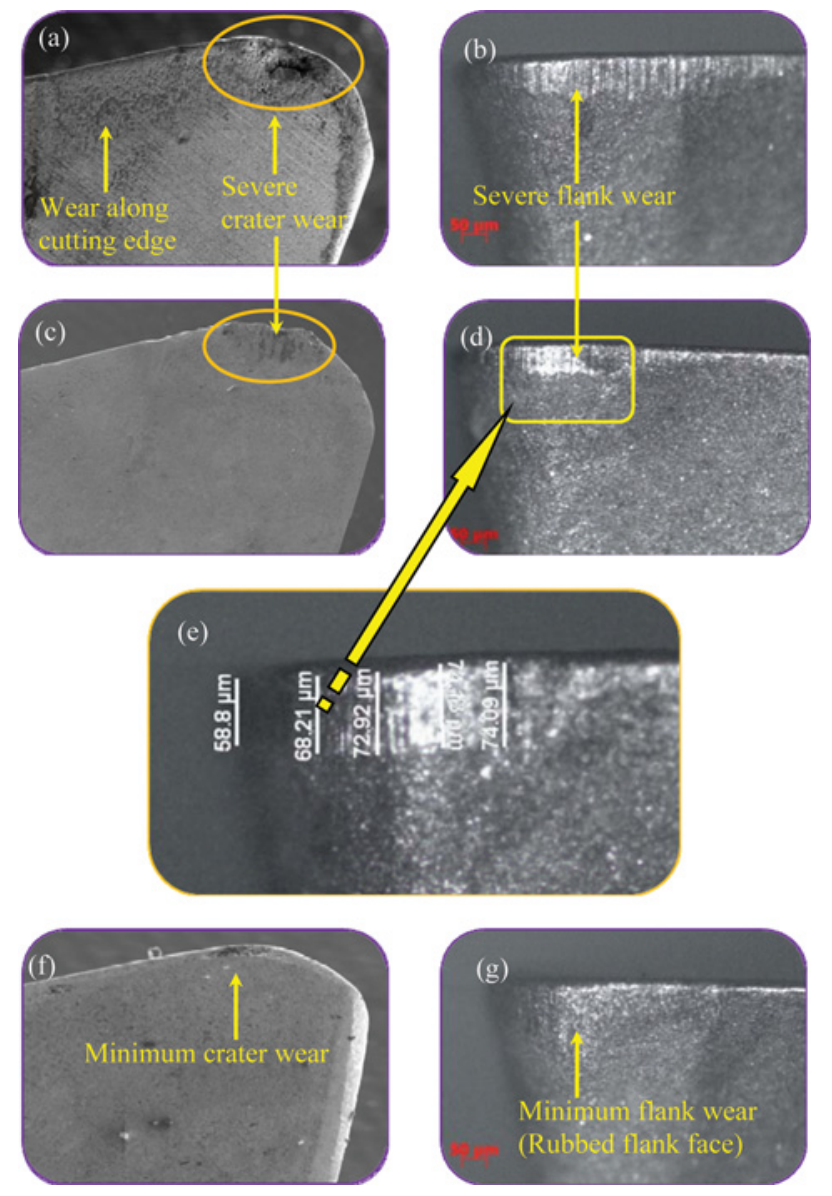

FIGURE 3.-Crater and flank wear in (a-b) dry turning, (c-d) turning with conventional cutting fluid, and (e-f) turning with $\mathrm{Al}_{2} \mathrm{O}_{3}$ based nanocutting fluid (color figure available online).

smooth. As machining time increases, the cutting edge wear gradually increases (sharpness decreases) either by deformation or by chipping. Thus, the cutting force also increases with machining time.

Figure 4 shows the variation of the cutting force with machining time. As the machining time increases, the cutting edge wears out gradually, irrespective of the presence or absence of the cutting fluid. Due to the absence of cutting fluid in dry machining, tool cutting edge wears out early because of the quick thermal softening of the cutting tool material in the machining zone. This leads to rapid increase in cutting force which is clearly seen around $\sim 120$ s (Fig. 4). The presence of conventional cutting fluid improves the life of cutting edge by providing cooling and lubrication (through conduction and convection process). So, tool hardness is retained for more time and rapid increase in the cutting force is observed around $\sim 210$ s of machining time. But in case of the nano-cutting fluid, rapid increase in cutting force is not observed because of improved cooling and lubrication. Though there is a continuous increase in the cutting force from the start of machining, while machining with nanocutting fluids, cutting force magnitude is smaller as compared to other techniques (Fig. 4). 


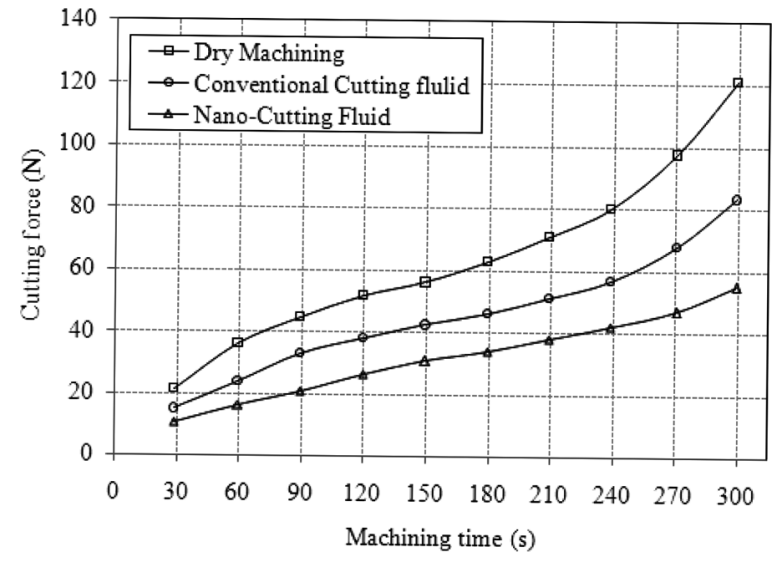

FIGURE 4.-Variation of cutting force with machining time for dry machining and machining with conventional and nano-cutting fluids.

\section{Chip Morphology and Chip Thickness}

In dry machining process, because of the high temperature in the shear zone, the work and tool materials get thermal softening. Since the workpiece material is much softer compared to the tool material, the continuous helical chips are generated. These chips try to weld to the top surface layers of tool rake face and take away thermally softened tool rake surface layers. Thus the chip thickness is high in dry machining process (Fig. 5). While machining with conventional cutting fluid, a hydrodynamic cutting fluid layer forms between chip and tool rake face. This hydrodynamic cutting fluid layer tries to push the chip away from the rake face. So, chip helix angle increases and even sometimes breaks the chip after a certain length. Thus, the chips are semilong with more helix angle (Fig. 5). In machining with nano-cutting fluid, due to impingement of $\mathrm{Al}_{2} \mathrm{O}_{3}$ nanoparticles on the chips, longer chips are forced to break, and this leads to tiny segmented chips. Nano-cutting fluid provides better cooling and lubricating properties which reduce the possibility of crater wear (Fig. 3(f)) and sticking of tool material on the back side of the chip; hence, chip

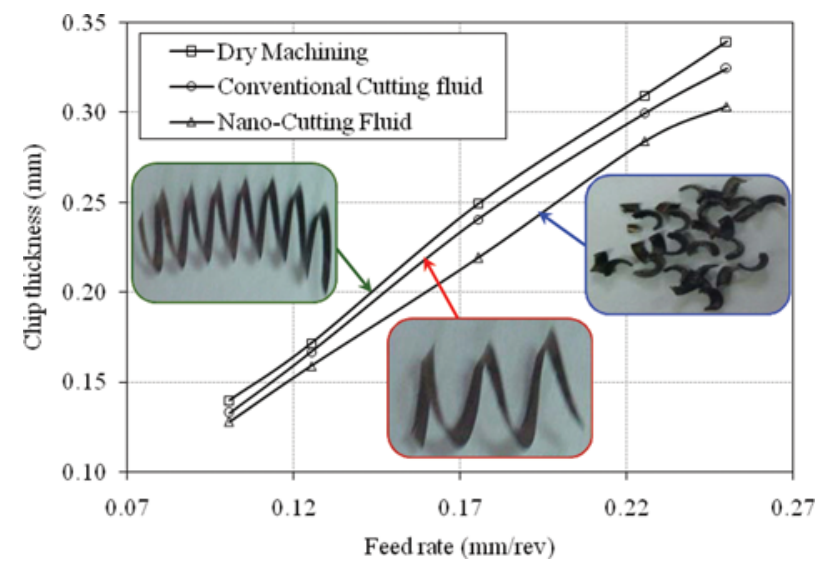

Figure 5.-Effect of feed on chip thickness during dry machining and machining with conventional cutting fluid as well as nano-cutting fluid (color figure available online).



FIGURE 6.-Variation of average surface roughness while dry machining and machining with conventional and nano-cutting fluid.

thickness is less when compared to the other two machining techniques (Fig. 5).

\section{Surface Roughness}

In the dry machining process, because of the absence of cutting fluid, the cutting edge wear occurs rapidly. So the machining process is no more smooth and the $\mathrm{R}_{\mathrm{a}}$ generated on the workpiece surface is high (Fig. 6). When machining with conventional cutting fluid, the cutting fluid presence protects the cutting edge partially due to its cooling and lubrication properties. So, the machining process is partially smooth and thus the $\mathrm{R}_{\mathrm{a}}$ generated is better compared to dry machining, (i.e., surface roughness reduces partially). But nano-cutting fluid greatly improves the wetting/lubricating properties of rake and flank regions. The net effect leads to better heat dissipation, so the machining process is smoother and causes retaining of hardness of tool cutting edge. Hence the surface roughness achieved during machining with nano-cutting fluid is minimum compared to other two machining conditions (Fig. 6).

\section{SUMMARY AND CONCLUSIONS}

In the present article, a comparative study of the performance during dry machining and machining with conventional and nano-cutting fluids is reported. It also investigates the effect on wettability characteristics of base fluids when nanoparticles are added. The following conclusions can be drawn based on the present work:

a. It is found that adding $1 \% \mathrm{Al}_{2} \mathrm{O}_{3}$ nanoparticles (by volume) to the conventional cutting fluid greatly enhances its wettability characteristics compared to pure water and conventional cutting fluid.

b. The great reduction of crater and flank wear is attributed to enhanced thermal properties, improvement in wettability, and lubricating characteristics of the nano-cutting fluid.

c. There is a reduction of $\sim 50 \%$ and $\sim 30 \%$ cutting force while machining with nano-cutting fluids 
compared to dry machining and machining with conventional cutting fluid, respectively.

d. There is $54.5 \%$ and $28.5 \%$ reduction in the $R_{a}$ value of the machined surface when nano-cutting fluid is used compared to dry machining and machining with conventional cutting fluid, respectively.

\section{REFERENCES}

1. Dutta, A.K.; Narasaiah, N.; Chattopadhyay, A.B.; Ray, K.K. Influence of microstructure on wear resistance parameter of ceramic cutting tools. Materials and Manufacturing Processes 2002, 17 (5), 651-670.

2. El-Hossainy, T.M.; El-Zoghby, A.A.; Badr, M.A.; Maalawi, K.Y.; Nasr, M.F. Cutting parameter optimization when machining different materials. Materials and Manufacturing Processes 2010, 25 (10), 1101-1114.

3. Denni Kurniawan, Noordin Mohd. Yusof, Safian Sharif. Hard machining of stainless steel using wiper coated carbide: Tool life and surface integrity. Materials and Manufacturing Processes 2010, 25 (6), 370-377.

4. El-Tamimi, A.M.; El-Hossainy, T.M. Investigating the tool life, cutting force components, and surface roughness of AISI 302 stainless steel material under oblique machining. Materials and Manufacturing Processes 2008, 23 (4), 427-438.

5. Gaitonde, V.N.; Karnik, S.R.; Figueira, L.; Paulo Davim, J. Analysis of machinability during hard turning of cold work tool steel. Materials and Manufacturing Processes 2009, 23 (4), 1373-1382.

6. Brnic, J.; Canadija, M.; Turkalj, G.; Lanc, D.; Pepelnjak, T.; Barisic, B.; Vukelic, G.; Brcic, M. Tool material behaviour at elevated temperatures. Materials and Manufacturing Processes 2009, 24 (7-8), 758-762.

7. Deng, W.J.; Xia, W.; Li, C.; Tang, Y. Ultrafine grained material produced by machining. Materials and Manufacturing Processes 2010, 25 (6), 355-359.

8. Denni Kurniawan, N.M.; Yusof, S.S. Hard machining of stainless steel using wiper coated carbide: Tool life and surface integrity. Materials and Manufacturing Processes 2010, 25 (6), 370-377.

9. Rama Kotaiah, K.; Srinivas, J.; Babu, K.J.; Kolla, S. Prediction of optimal cutting states during inward turning: An experimental approach. Materials and Manufacturing Processes 2010, 25 (6), 432-441.

10. Nirmal, S.; Sehgal, K.R.; Sharma, V.S. Cryogenic treatment of tool materials: A review. Materials and Manufacturing Processes 2010, 25 (10), 1077-1100.
11. Ganesha Prasad, M.S.; Drakshayani, D.N. Studies on passive cooling techniques in dry machining. Materials and Manufacturing Processes 2010, 25 (6), 360-369.

12. Paulo Davim, J.; Sreejith, P.S.; Silva, J. Turning of brasses using minimum quantity of lubricant (MQL) and flooded lubricant conditions. Materials and Manufacturing Processes 2007, 22 (1), 45-50.

13. Li, Q.; Yimin, X. Convective heat transfer and flow characteristics of $\mathrm{Cu}$-water nano-fluid. Science in China (Series E) 2002, 45 (4), 408-416.

14. Yang, Y.; Zhang, Z.G.; Grulke, E.A.; Anderson, W.B.; Wu, G. Heat transfer properties of nano-particle-in-fluid dispersions (nano-fluids) in laminar flow. International Journal of Heat and Mass Transfer 2005, 48, 1107-1116.

15. Wen, D.; Ding, Y. Experimental investigation into convective heat transfer of nano-fluids at the entrance region under laminar flow conditions. International Journal of Heat and Mass Transfer 2004, 48, 5181-5188.

16. Ding, Y.; Alias, H.; Wen, D.; Williams, R. Heat transfer of aqueous suspensions of carbon nano-tubes (CNT nanofluids). International Journal of Heat and Mass Transfer 2006, 49, 240-250.

17. Das, S.K.; Choi, S.U.S.; Yu, W.; Pradeep, T. A review of nanofluids: Science and technology. Materials and Manufacturing Processes 2009, 24 (5), 600-601.

18. Srivatsan, T.S. A review of contact angle, wettability, and adhesion. Materials and Manufacturing Processes 2010, 25 (6), 526.

19. Das, S.K.; Putra, N.; Thiesen, P.; Roetzel, W. Temperature dependence of thermal conductivity enhancement for nanofluids. ASME Trans. J. Heat Transfer 2003, 125, 567-574.

20. Kim, S.J.; Bang, I.C.; Buongiorno, J.; Hu, L.W. Effect of nano-particles deposition on surface wettability influencing boiling heat transfer in nano-fluids. Applied Physics Letters 2006, 89, 153107.

21. Wasan, D.T.; Nikolov, A.D. Spreading of nano-fluids on solids. Nature 2003, 423, 156-159.

22. Wang, X.; Mujumdar, A.S. Heat transfer characteristics of nano-fluids: A review. International Journal of Thermal Sciences 2007, 46, 1-19.

23. Masuda, H.; Ebata, A.; Teramea, K.; Hishinuma, N. Alteration of thermal conductivity and viscosity of liquid by dispersing ultra-fine particles. Netsu Bussei 1993, 4 (4), 227-233.

24. Choi, S.U.S. Enhancing thermal conductivity of fluids with nano-particles. Developments and Applications of NonNewtonian Flows 1995, 231 (66), 99-105. 